\title{
Increasing Access for Economically Disadvantaged Students: The NSF/CSEM \& S-STEM Programs at Louisiana State University
}

\author{
Zakiya S. Wilson • Sitharama S. Iyengar • \\ Su-Seng Pang $\cdot$ Isiah M. Warner $\cdot$ Candace A. Luces
}

Published online: 17 November 2011

(c) The Author(s) 2011. This article is published with open access at Springerlink.com

\begin{abstract}
Increasing college degree attainment for students from disadvantaged backgrounds is a prominent component of numerous state and federal legislation focused on higher education. In 1999, the National Science Foundation (NSF) instituted the "Computer Science, Engineering, and Mathematics Scholarships" (CSEMS) program; this initiative was designed to provide greater access and support to academically talented students from economically disadvantaged backgrounds. Originally intended to provide financial support to lower income students, this NSF program also advocated that additional professional development and advising would be strategies to increase undergraduate persistence to graduation. This innovative program for economically disadvantaged students was extended in 2004 to include students from other disciplines including the physical and life sciences as well as the technology fields, and the new name of the program was Scholarships for Science, Technology, Engineering and Mathematics (S-STEM). The implementation of these
\end{abstract}

Z. S. Wilson $(\bowtie) \cdot$ I. M. Warner

Office of Strategic Initiatives and Department of Chemistry, Louisiana State University, Baton Rouge, LA 70803, USA

e-mail: zwilson@1su.edu

\section{S. S. Iyengar}

Department of Computer Science, Louisiana State University, Baton Rouge, LA 70803, USA

S.-S. Pang

Office of Strategic Initiatives and Department of Mechanical Engineering, Louisiana State University, Baton Rouge, LA 70803, USA

C. A. Luces

Office of Strategic Initiatives, Louisiana State University, Baton Rouge, LA 70803, USA two programs in Louisiana State University (LSU) has shown significant and measurable success since 2000, making LSU a Model University in providing support to economically disadvantaged students within the STEM disciplines. The achievement of these programs is evidenced by the graduation rates of its participants. This report provides details on the educational model employed through the CSEMS/S-STEM projects at LSU and provides a path to success for increasing student retention rates in STEM disciplines. While the LSU's experience is presented as a case study, the potential relevance of this innovative mentoring program in conjunction with the financial support system is discussed in detail.

Keywords Mentoring - Economically disadvantaged .

Retention · Persistence - Undergraduates - STEM curricula · Academically talented students · National Science Foundation $\cdot$ Technology driven education

\section{Introduction}

Theodore Roosevelt, an advocate of education, extolled that "A man who has never gone to school may steal from a freight car; but if he has a university education, he may steal the whole railroad." Education is the foundation for economic development and prosperity, and it is the access point by which groups from all backgrounds are able to capture the American dream.

While African Americans, Latin Americans, and Native Americans comprise a visible percentage of the US population, these groups continue to be seriously underrepresented in many disciplines that impact the nation's economy, largely the science, technology, engineering, and mathematics (STEM) disciplines. Whether looking at this 
in terms of ensuring national security, cultivating the continued prosperity of America in an increasingly global economy, or increasing access for a culturally diverse citizenry, it is a national imperative to provide opportunities for young minds from all backgrounds to have access to higher education, particularly within the STEM disciplines. It is the responsibility of stakeholders in education to support educational reform that improves the learning experiences of all students. To help the United States maintain its competitive edge in global markets, support is particularly important in the sciences and mathematics (Committee on Prospering in the Global Economy of the 21st Century (US) and Committee on Science Engineering and Public Policy (US) 2010; Galama et al. 2007; Committee on Prospering in the Global Economy of the 21st Century and Committee on Science Engineering and Public Policy 2007; National Academy of Sciences et al. 2011).

In 1999, the National Science Foundation (NSF) instituted the "Computer Science, Engineering, and Mathematics Scholarships" (CSEMS) program; this endeavor was initiated to provide greater access and support for academically talented students from economically disadvantaged backgrounds. Designed to provide financial support and mentoring to lower income students, the NSF/ CSEMS initiative was developed and implemented to improve student retention and graduation within the mathematical, computational science, and engineering disciplines. In 2004, NSF extended the program to include the physical and biological sciences as well as other STEM disciplines and renamed the program, Scholarships for Science, Technology, Engineering, and Mathematics (S-STEM).

Since their inauguration, the NSF/CSEMS and S-STEM programs have provided strategic opportunities to test educational models designed to improve the retention of students in STEM disciplines, particularly those from economically disadvantaged and underrepresented backgrounds. The implementation of these two programs in Louisiana State University (LSU) has shown significant and measured success since 2000, and LSU has become a Model University in providing support to economically disadvantaged students within STEM disciplines. The success of these programs at LSU is evidenced by the graduation rates of all LSU/CSEMS and S-STEM participants, of which nearly ninety percent have graduated with STEM degrees! This report provides an analysis of the key features of the CSEMS and S-STEM initiatives at LSU and how systemic improvements have led to the graduation rate gains that epitomize LSU as a Model University. While LSU's experience is presented as a case study, the potential relevance of this innovative mentoring program in conjunction with the financial support system is discussed in detail.

\section{Model design}

As Roosevelt maintained, undergraduate education is a primary access point for economic success, and many scholars and political leaders have asserted that student persistence in the STEM disciplines is important for the economic future of the US (Committee on Prospering in the Global Economy of the 21st Century and Committee on Science Engineering and Public Policy 2007; Galama et al. 2007; National Academy of Sciences et al. 2011). Unfortunately, less than half of the US students who enter into STEM undergraduate curricula as freshmen will actually graduate with a STEM degree (Hayes et al. 2009; Graduation Gaps for Science Majors 2010; Wilson et al. 2011). Minority groups, underrepresented in these fields, have even higher attrition rates from these disciplines (Fig. 1). While disparities in retention for minority groups are well defined, generally, disparities in student retention and graduation rates in STEM disciplines for economically disadvantaged students are not often discussed. Nevertheless, low-income students face inherent challenges in financing their higher education aspirations while pursuing academically rigorous curricula, like those within the STEM disciplines (Hossler et al. 2009).

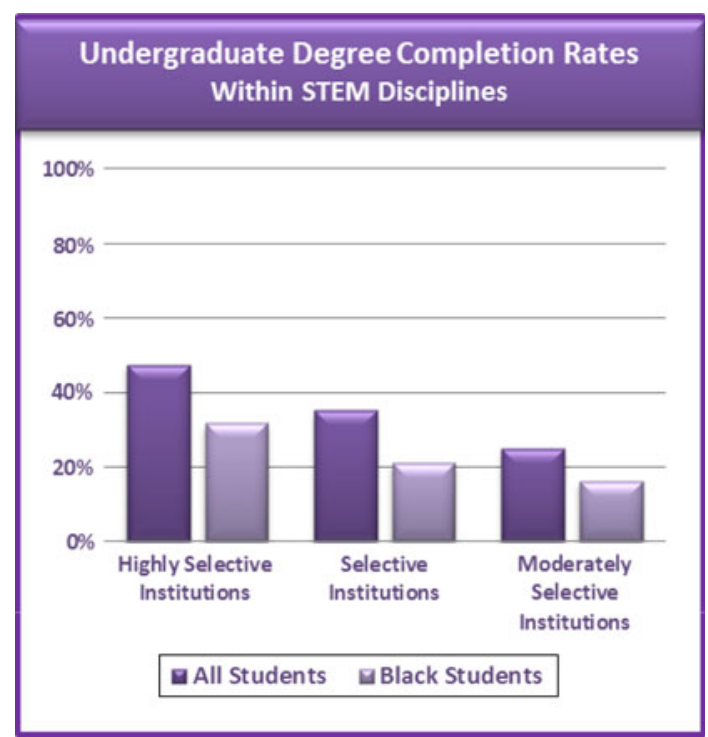

Fig. 1 Six-year Graduation Rates for US Colleges and Universities, collected by the Center for Institutional Data Exchange and Analysis at the University of Oklahoma. The graduation rates are given for freshmen entering into STEM undergraduate curricula and continued through to graduate with a STEM undergraduate degree. Institutional selectivity is based on entrance requirements. Highly selective institutions require a minimum ACT Score of 24.0 or a minimum SAT score of 1,100 . Selective institutions will allow ACT Scores between 22.5 and 24.0 or SAT scores between 1,045 and 1,100 for admission. Moderately selective institutions will allow ACT Scores between 21.0 and 22.5 or SAT scores between 990 and 1,044 for admission 
Retention research lists "lack of adequate financing" as a major factor for many students leaving college (Cabrera and Fries-Britt 2008; Seidman 2005). The lack of adequate financing affects many students at Louisiana State University (LSU). Approximately $25 \%$ of the 23,000 undergraduate students are eligible to receive federal aid (either US Department of Education Pell Grant or Subsidized Stafford Loan) (Lousiana state university office of budget and planning). Financially disadvantaged students face significant obstacles in finding sufficient funding to complete their college studies. Disadvantaged students who decide to remain are often times burdened with obtaining loans and/or working long hours. Due to financial constraints, many academically talented students are not able to maintain the level of achievement consistent with their potential.

The major focus of the NSF/CSEMS and S-STEM projects at LSU has been to construct an academic support program that meets the needs of financially disadvantaged students without over-burdening these with exhaustive program requirements. The objectives of this project were to recruit financially disadvantaged students, to retain them, and to enhance their educational experiences. Specifically, program efforts worked to:

(1) Recruit academically talented students ranging from high school seniors to existing LSU students as well as nearby community college, Baton Rouge Community College (BRCC), students who have demonstrated great potential for success, especially women and minorities in the physical, life, and computational sciences and mathematics. BRCC is located in the same city as LSU. Transfer articulation between BRCC and LSU has recently established.

(2) Retain these students through the incorporation of academic support and professional development.

(3) Provide students with mentoring from faculty, Office of Strategic Initiatives (OSI) staff, and a cohort of students in other OSI undergraduate education programs.

(4) Provide students with (optional) research training opportunities.

(5) Enhance the educational experience of students through workshops/seminars, K-12 and community outreach opportunities.

(6) Promote intercultural participation among non-minority and minority students.

(7) Expand the proposed program activities to accommodate a student population larger than the scholarship recipients.

\section{Infrastructure and Implementation}

The conundrum of student persistence in STEM disciplines has been investigated from a variety of different avenues.
Minority students who have participated in studies on this topic have cited campus and classroom climate as well as the lack of mentoring as major factors leading to STEM attrition (Hausmann et al. 2007; Locks et al. 2008). Additional studies have found that students' academic selfefficacy and precollege preparedness both play roles in student success and persistence in STEM disciplines (Braxton et al. 2004). While self-efficacy does include such things as study and time management skills, it also includes precollege background and the effective navigation of college acclimation.

Further data exemplify the disparity in student persistence at the precollege level. Studies on high school graduation rates show that $72 \%$ of white students who began high school in 1997 graduated in 2001, while only $52 \%$ of Latino and $51 \%$ of African-American students graduated within 4 years. Finally, of those students who enrolled in college in the fall of $1998,59 \%$ of white students graduated in 4 years; in contrast, only $36 \%$ of Latino students and only $40 \%$ of African-American students graduated 4 years later.

Whether considering student persistence or student achievement at the precollege, the data reveals a general pattern of disparities for students of color across a variety of measures. Summarily, minority students face challenges in persistence at the precollege level and under-preparation for advanced study in STEM disciplines at the undergraduate level. Consequently, the duality of disparities lead to "pipeline" challenges at the undergraduate level and is operationalized as "leakage" in the pipeline. The two prime negative factors that contribute towards the 'leakage rate' of minority students at the undergraduate level are economic and academic backgrounds. The former includes socioeconomic background which inadvertently leads to students matriculation through public school systems with less rigorous academic programs, fewer advanced placement courses in the sciences and mathematics, and a general under-preparation for advanced study in the STEM disciplines.

Recognizing that many factors contribute to student persistence at the undergraduate level, the CSEMS/ S-STEM education model was designed to integrate interventions that address the varying factors contributing to persistence. Herein, technical training and professional development were paired with mentoring in a strategic approach designed to empower students while provide an academic support infrastructure that could guide them in realizing their potential. This conglomerate of approaches formed the bases of the education model (Fig. 2), which is based on a core belief that mentoring and training are key ingredients for sustaining student interest in STEM disciplines and their efficacy for navigating educational pathways within these disciplines. 
Fig. 2 Comprehensive approach for increasing the success of economically disadvantaged students in STEM undergraduate curricula

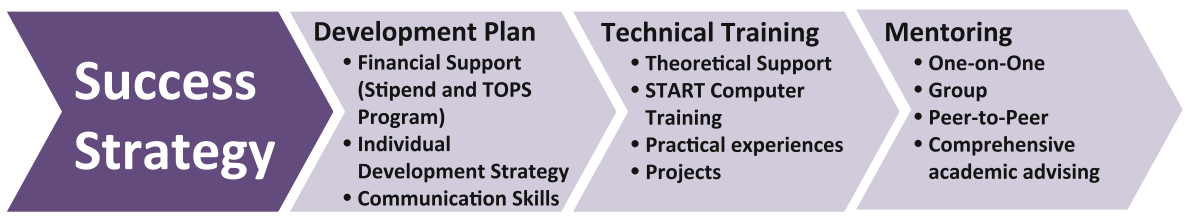

The strategy of this approach is simple and can be adopted easily by any other institution. The comprehensive set of strategies for bringing students to success, especially for minorities are summarized as: Integration of academic support, enhancement, and professional activities in information technology training; Academic enhancement activities that includes personal mentoring and career placements, and Outreach activities include involvement in K-12 education, industrial training and field trips.

The financial and social gaps between 'disadvantaged' and 'advantaged' groups are significant. To address the financial gaps, the recruited students were offered annual scholarship of $\$ 3,000-\$ 4,000$ combined with the tuition waiver provided through Louisiana's Tuition Opportunity Program for Students (TOPS) program over the period of project. The stipend paid proved to be a critical recruitment tool to encourage and sustain more talented, financially disadvantaged high school students to consider a collegiate level education. The funds from this project have served as the seed money to establish scholarships and enhancements for financially needy and academically talented students in STEM.

To address the social gaps, CSEMS/S-STEM Scholars received additional mentoring and research training. The design structure of four key activities forms the foundation of these interactions and includes the following: (Fig. 3)

\begin{tabular}{|c|c|}
\hline \multicolumn{2}{|c|}{ PROGRAM ACTIVITIES } \\
\hline $\begin{array}{l}\text { Recruiting Students } \\
\text { - Residency } \\
\text { - Financial Needs } \\
\text { - Statement of Purpose } \\
\text { - Letter of } \\
\text { recommendations } \\
\text { - Interview }\end{array}$ & $\begin{array}{l}\text { Academic Enhancement } \\
\text { - Monthly Seminars } \\
\text { - Emphasis on } \\
\text { communication skills } \\
\text { - Personal Mentoring } \\
\text { - Motivation for repelling } \\
\text { courses } \\
\text { - Career Placements }\end{array}$ \\
\hline $\begin{array}{l}\text { Outreach Activities } \\
\text { Educational Outreach: } \\
\text { K-12 education } \\
\text { - Industrial Outreach: } \\
\text { NASA, DOW Chemical } \\
\text { etc. } \\
\text { - Business Engineering } \\
\text { - Computer Science } \\
\text { Facilities }\end{array}$ & $\begin{array}{l}\quad \text { IT Training } \\
\text { - Essential Computer Skills } \\
\text { - Technical Workshops } \\
\text { - START Program } \\
\text { - Short Term Projects }\end{array}$ \\
\hline
\end{tabular}

Fig. 3 LSU/S-STEM programmatic activities
- Recruitment of Students

- Information Technology Training,

- Academic Enhancement Activities

- Educational and Industrial Outreach.

Through the collaboration of the Center for Academic Success (CAS), the Office of Strategic Initiatives (OSI), and the Mathematics Consultation Clinic, the academic enhancement and outreach activities were designed, implemented, and sustained. The OSI, Department of Computer Science, CAS, and faculty members throughout the science and math disciplines have provided active mentoring and academic assistance for the Scholars to maximize their chance for academic success. While the Scholars were provided with various enhancement opportunities including technical training and introduction to research, the mentoring component was often cited by students as the most significant contributor to their persistence within their STEM undergraduate curricula. Further details on this component are provided in the following section.

\section{Mentoring: A Significant Contributor to Undergraduate Student Persistence}

\section{Individual Academic/Research Mentor for Each OSI} Program Student

In the past, faculty mentors have been assigned to students upon acceptance into the program. Students could elect to either secure research with their assigned mentor, who would serve as both a faculty and research mentor, or secure research independently. To support the goal of developing autonomous scholars, current practice has been to provide students with the necessary resources for developing effective faculty-student relationships and to encourage them to secure research mentors based on their individual research interests. Program managers provide guidance to students throughout this process. Faculty mentors attend a training session sponsored by OSI, and each mentor agrees to write his or her student a letter of introduction, and to meet with the student several times per year. Faculty mentors also give research presentations during Summer Bridge, as well as during the academic year and attend several program social events and dinners. Additionally, a faculty liaison is identified for each 
participating department. This faculty liaison will pair students with their respective mentors, as well as act as a general advocate for CSEMS/S-STEM in the department.

\section{Individual Mentoring and Counseling}

OSI program students are required to meet with OSI staff each semester. Students on program academic warning or probation are required to meet a minimum of four times a semester. During mentoring meetings, the scholar's academic progress is discussed and students are advised accordingly. Some students require counseling sessions and will meet with the program counselor. When appropriate, students are referred to other resources on campus, including Career Services, the Honors College, Center for Academic Success, the Writing Center, various on-campus tutorial centers, the Center for Freshman Year, and the advising services available through their major colleges. In some instances, the students may also be advised to meet with their professor. Any scholar who receives less than a $\mathrm{C}$ on any graded test or paper must seek formal tutoring and verification sheets must be turned in weekly. The program staff monitors the scholar's progress by verifying the completion of the tutoring requirement via mentoring meetings and email correspondence. Students are introduced to learning and study strategies regarding topics such as metacognition, time management, stress, test anxiety, and discipline-specific learning strategies by Dr. Saundra Y. McGuire, Assistant Vice Chancellor for Learning and Teaching and former Director of LSU Center for Academic Success. Dr. McGuire is a collaborator on several OSI Mentoring projects and has published articles and book chapters that help faculty teach in ways that actively engage students in the learning process. The program managers provide guidance to the students throughout this process.

\section{Participants and Results}

The recruitment and selection of students are based on their residency, financial needs, GPA, statement of purpose, letters of recommendation, and an interview. The project's management team works collaboratively with the university's Financial Aid and Scholarship Office to identify economically disadvantaged candidates for participation in the project. An extensive recruitment agenda is aimed at this group and includes mailings, applications, and interviews with program staff.

Based on the financial needs, academic records and future goals, low-income STEM undergraduate students were selected to participate, of which $55 \%$ were underrepresented by race and/or ethnicity. These selected scholars where high-achieving students with financial need.
To date, 243 students have participated in the OSI/S-STEM Program. With an average cumulative GPA of 3.345, this very diverse group of students has included African Americans (49\%), Caucasians (35\%), Asians (10\%), and Hispanic (4\%), all of which have been US citizens or permanent residents (Fig. 4). Forty-three percent of the participants have been women and fifty-seven percent have been men.

\section{Graduation Rates in STEM}

Financial aid for low-income students was found to be critical to ensuring persistence in undergraduate programs. There has been some anecdotal information on the program's impact on student persistence; and these have largely been collected in mentoring meetings between students and program manager/academic counselor. Nevertheless, the most poignant evidence of the program's impact is seen through the retention rates of students in STEM disciplines through graduation.

The larger comparison of the total population of STEM students at LSU to those high financial needs students participating in the S-STEM project offers some insight. In the current grant, $94 \%$ of participants have been retained. This is a very significant increase over the six-year graduation rates of students not enrolled in the program, which hovers around $34 \%$ for students who entered LSU as STEM majors since 1998 through 2003. Beyond this data, financial aid has been shown to have significant impacts on student persistence at other institution and these findings have been well in line with this data.

\section{Improvement in Recruitment and Retention Rates}

The results of three CSEMS/S-STEM projects demonstrate the clear success of its model in retaining student until graduation (Fig. 5). All these projects included undergraduates in varying STEM majors at LSU. To gain some insight into the projects' retention of STEM majors, data

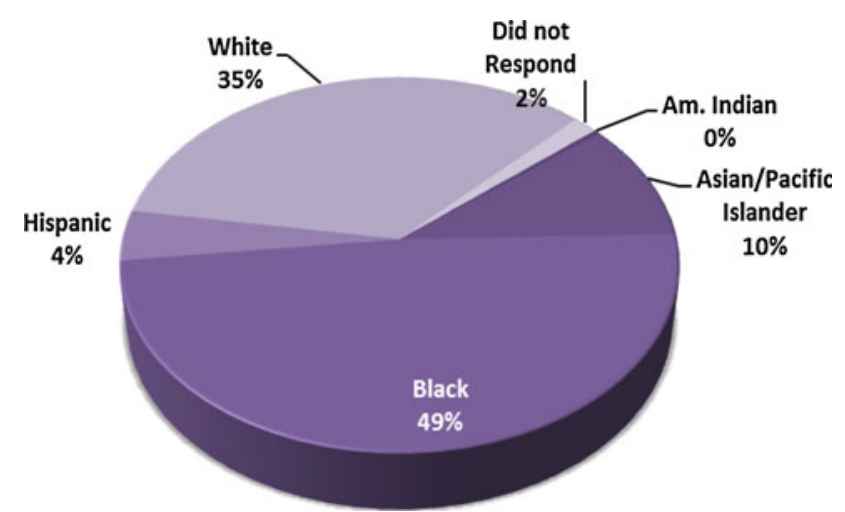

Fig. 4 Demographics of the LSU-S-STEM Scholars, by ethnicity 
was gathered on the overall LSU six-year graduation rates in STEM disciplines. On average, approximately $34 \%$ of freshmen entering into STEM disciplines at LSU actually complete a STEM degree. This data include students from majority and minority groups as well as students from economically disadvantaged groups.

STEM retention rates are shown for the three prior projects with LSU STEM majors and a select number of colleges and universities as polled by the Center for Institutional Data Exchange and Analysis. The LSU CSEMS/S-STEM programs chronicle the positive impact of its financial support working in concert with a wellstructured mentoring program on student retention in STEM disciplines. Notably over $50 \%$ of all participants have been underrepresented by ethnicity, and the positive impacts on STEM retention and graduation are seen uniformly for both minority and majority students.

\section{Concluding Remarks}

Using NSF/CSEMS and NSF/S-STEM projects, LSU/OSI has developed a very successful mentoring program for economically disadvantaged students based on the following indicators: (a) The costs for college education have been leveraged efficiently and effectively; (b) Graduation rates have increased; (c) More students have received regional/national awards and recognitions; and (d) Student performance (e.g., GPA) has improved. Achieving all of these for college students has been a challenge in higher

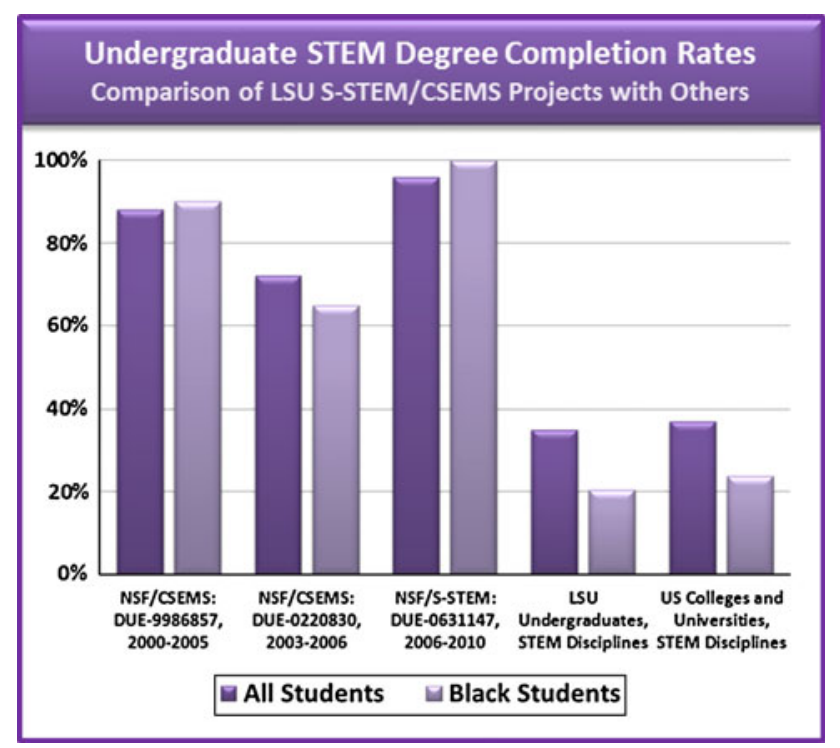

Fig. 5 Six-year Graduation Rates in STEM Degree programs for US Colleges and Universities, LSU, and LSU/S-STEM participants. The graduation rates are given for freshmen entering into STEM undergraduate curricula and continued through to graduate with a STEM undergraduate degree education, especially for minority and female students in the STEM disciplines. LSU/OSI has created numerous innovative mentoring activities to achieve these impressive results. OSI was established to break disciplinary barriers and change the traditional way of conducting education and mentoring. Herein, LSU resources have been leveraged to enhance the synergy and positive "composite action" among the existing projects. OSI Mentoring Programs have and continue to: (1) nurture students in an interdisciplinary environment so that they become Inspirational Teachers, Exemplary Mentors, and Effective Leaders; (2) create and implement programs that broaden the participation of more diversified students; (3) enhance the academic environment to better support students, who subsequently transfer their service to K-12 education. Furthermore, CSEMS/S-STEM Scholars are able to readily relate to a broad spectrum of individuals: academicians, K-12 teachers and students, industry personnel, and the public in general. It is anticipated that all OSI program students will exert a positive and ethical influence in the community as Model Citizens.

The noticeable success of the CSEMS/S-STEM projects at LSU is largely attributed to its mentoring strategy. Pairing multifaceted mentoring approaches with financial aid has addressed the social and financial gaps that economically disadvantaged students experience in higher education settings. This has helped students to better acclimate to the university while increasing students access to campus resources, and this acclimation has been a direct factor in participants graduation rates.

The CSEMS/S-STEM efforts at LSU have demonstrated that financial aid alone does not address all of the factors leading to undergraduate attrition. The strategic pairing of scholarships with mentoring and training programs provided a level of academic and social support that is critical to increasing student persistence.

\section{Sustainability}

OSI has been permanently established at LSU since 2001 . All of the infrastructures, including space and facilities, are available. In addition to the designated Vice Chancellor and Associate Vice Chancellor for Strategic Initiatives, LSU has also provided several permanent staff positions for OSI, including secretary, business manager, counselor, office manager, several program managers, several student workers, etc. OSI has demonstrated its sustainability in structural changes that will increase all mentoring activities (student retention, graduation rate, etc.) in the future. Therefore, OSI has been institutionalized by LSU and the student support programs will be continuous. Meanwhile, LSU is in the process of establishing an "Endowment Account" through industries and alumni for extending further support of OSI student programs. In addition, 
Louisiana's Board of Regents (BoR) supports educational and research programs within STEM disciplines, and OSI has already started receiving support from BoR for their student programs on a yearly basis since 2008 .

Acknowledgements The authors are very grateful to National Science Foundation for their funding many of these projects. We are also grateful to all students in their participation in this work. This study was partially sponsored by the National Science Foundation under project numbers: NSF/DUE-9986857, NSF/DUE-0220830, and NSF/ DUE-0631147.

Open Access This article is distributed under the terms of the Creative Commons Attribution Noncommercial License which permits any noncommercial use, distribution, and reproduction in any medium, provided the original author(s) and source are credited.

\section{References}

Braxton JM, Hirschy AS, \& McClendon SA (2004) Understanding and reducing college student departure. ASHE-ERIC higher education report, vol 30. Jossey-Bass, San Francisco

Cabrera AF, Fries-Britt S (2008) Minority student retention: the best of the journal of college student retention: research, theory, and practice. [Book Review]. Rev Hig Educ 31(4):508-510

Committee on Prospering in the Global Economy of the 21st Century (US), \& Committee on Science Engineering and Public Policy (US) (2010) Rising above the gathering storm revisited: rapidly approaching category 5. National Academies Press, Washington, DC

Committee on Prospering in the Global Economy of the 21st Century, \& Committee on Science Engineering and Public Policy (2007)
Rising above the gathering storm: energizing and employing America for a brighter economic future. National Academies Press, Washington, DC

Galama T, Hosek JR, National Defense Research Institute (US) (2007) Perspectives on US Competitiveness in science and technology. Rand Corp, Santa Monica, CA

Graduation Gaps for Science Majors (2010, February 17) Inside Higher Ed

Hausmann LRM, Schofield JW, Woods RL (2007) Sense of belonging as a predictor of intentions to persist among African American and white first-year college students. Res High Educ 48(7):803-839

Hayes RQ, Whalen SK, Cannon B (2009) Csrde stem retention report, 2008-2009. Center for Institutional Data Exchange and Analysis, University of Oklahoma, Norman

Hossler D, Ziskin M, Gross JPK, Kim S, Cekic O (2009) Student aid and its role in encouraging persistence. In: Smart JC (ed) Higher education: handbook of theory and research, vol 24. Springer, Netherlands, pp 389-425

Locks AM, Hurtado S, Bowman NA, Oseguera L (2008) Extending notions of campus climate and diversity to students' transition to college. Rev High Educ 31(3):257-285

National Academy of Sciences, National Academy of Engineering, \& Institute of Medicine (2011) Expanding underrepresented minority participation: America's science and technology talent at the crossroads. National Academies Press, Washington, DC

Seidman A (ed) (2005) College student retention: formula for student success. American Council on Education - Oryx Press Series on Higher Education, Washington, DC

Wilson Z, Holmes L, deGravelles K, Sylvain M, Batiste L, Johnson M, et al (2011) Hierarchical mentoring: a transformative strategy for improving diversity and retention in undergraduate stem disciplines. J Sci Educ Technol. doi:10.1007/s10956-011-9292-5

Lousiana State University Office of Budget and Planning. http:// www.bgtplan.lsu.edu 